\title{
Association among Vitamin D Deficiency, Type 1 Diabetes Mellitus and Glycemic Control
}

\author{
Abdulmoein E Al-Agha ${ }^{1,2 *}$ and Ihab A Ahmad ${ }^{3}$
}

${ }^{1}$ Faculty of Medicine, King Abdulaziz University, Jeddah, Saudi Arabia

${ }^{2}$ Department of Pediatrics, Faculty of Medicine, King Abdulaziz University, Jeddah, Saudi Arabia

${ }^{3}$ Department of Pediatrics, Faculty of Medicine, Zagazig University, Zagazig, Egypt

\begin{abstract}
Background: Studies have identified that the deficiency of vitamin $D$ is strongly connected with diabetes mellitus type 1. Vitamin D has the capability to control increased blood glucose level.

Purpose: The study appraises the association among vitamin D deficiency, type 1 diabetes mellitus, and glycated hemoglobin among children.

Methods: Around, 226 diabetic children were selected for this retrospective study from outpatient department of King Abdul Aziz University Hospital. Majority of the participants were female individuals, with the rate of $61.1 \%$ and were divided into three categories, based upon the rate of vitamin D deficiency. Every participant of the study was taking intensive insulin therapy.

Results: The findings of the study have shown that $77 \%$ of the diabetic patients had reduced level of vitamin $D$ in total. The study identified, from the evaluation between $\mathrm{HbA} 1 \mathrm{c}$ control and vitamin $\mathrm{D}$ status, that $66 \%$ of the diabetic and vitamin $\mathrm{D}$ deficient participants were poorly controlled $(\mathrm{HbA} 1 \mathrm{c}>9 \%)$.

Conclusion: Vitamin D deficiency among the patients of diabetes mellitus type 1 was extremely high and was closely related with glycemic control. Additionally, the findings of the study have demonstrated therapeutic implications that the supplements of vitamin D have the potential to manage glucose level.
\end{abstract}

Keywords: Vitamin D deficiency; Glycemic control; Type 1 diabetes mellitus

\section{Introduction}

Fat-soluble compounds, which are responsible for accelerating the process of absorption in the intestines, are termed as 'Vitamin D' (vit D). Vitamin D is usually represent as vit D. Numerous benefits are strongly connected with the normal levels of vit $\mathrm{D}$ in the human body. It is a fact that the human beings should maintain the level of vit $\mathrm{D}$ in their body for the normal regulation of the body processes. There are three major sources for getting vit $\mathrm{D}$. The first and major source for getting vit $\mathrm{D}$ is sunlight. Dietary elements are considered as the second major source for gaining vitamin D. Supplements are third major source for the intake of vit $\mathrm{D}$. To overcome the decreased levels of vit D in patients, Vit D supplements are manufactured in laboratory settings. It has been identified that the normal levels of vit $\mathrm{D}$ is extremely significant for the human body, as it leads to various other complications.

Poor levels of vit $\mathrm{D}$ in the body will make a direct impact on the normal functioning of different systems and organs. A study has revealed that bones and tendons require sufficient amount of vit $D$ for strength and power. Lower levels of vit $\mathrm{D}$ in the human body is known as deficiency. The condition of vit $\mathrm{D}$ deficiency usually results in rickets among children. Rickets can be defined as a serious medical condition that affects bone and relative tendons [1]. Thus, maintaining the normal levels of vit $\mathrm{D}$ is necessary for appropriate regulation of the systemic processes.

It has been specified by some of the research based studies that there is a strong connection between the deficiency of vit D and the incidence of type 1 diabetes mellitus (T1DM). It has been proved by the a research study that the death of islet cells and its supplements can be easily prevented by the vit $\mathrm{D}$, which in turn, will enhance the production of insulin [1-11]. It has been mentioned by several studies that the regulation of beta cells can be negatively affected by the lower level of vit D [12].

Statistical reports of a study revealed that the prevalence of vit $\mathrm{D}$ deficiency is increasing day by day, particularly in the western and eastern countries, which is approximately $15 \%$ to $16 \%$ among the diabetic patients. Vit $\mathrm{D}$ has a capability to transform the metabolic process of glucose, along with other processes. The results of this study also demonstrated the immune-modulatory and anti- inflammatory features of vit D [8]. Hence it can be deduced that the auto-immune pathology of T1DM can be affected by the deficiency of vit D.

It has been estimated by another study that there is a strong connection between the complications of TIDM and the vit D deficiency. This study found out that the symptoms of diabetes are recurrent as the levels of vit $\mathrm{D}$ are lower than the normal limits [9]. There is a chance that the diabetic patients can develop the lower levels of $25 \mathrm{OHD}$. Decrease in the levels of $25 \mathrm{OHD}$ leads to the increased levels of glucose. Similar to this, the reduced levels of 25OHD is also

*Corresponding author: Dr. Abdulmoein E Al-Agha, DCH, FRCPCH, Faculty of Medicine, King Abdulaziz University, Jeddah, Kingdom of Saudi Arabia, Tel: +96626408306; Fax: +96626403841; E-mail: aagha@kau.edu.sa

Received July 10, 2015; Accepted August 22, 2015; Published August 26, 2015

Citation: Al-Agha AE, Ahmad IA (2015) Association among Vitamin D Deficiency, Type 1 Diabetes Mellitus and Glycemic Control. J Diabetes Metab 6: 594. doi:10.4172/2155-6156.1000594

Copyright: @ $2015 \mathrm{Al}-\mathrm{Agha} \mathrm{AE}$, et al. This is an open-access article distributed under the terms of the Creative Commons Attribution License, which permits unrestricted use, distribution, and reproduction in any medium, provided the original author and source are credited. 
related to the increased levels of glycated hemoglobin [10]. Thus, it was proved that the diabetic patients commonly suffer from high levels of vit $\mathrm{D}$ deficiency. It is therefore suggested that the vitamin $\mathrm{D}$ levels of diabetic patients should be assessed on regular basis, to ensure proper healthcare delivery [9].

\section{Objective of the study}

The study has formulated desired outcomes to evaluate the connection between vit D and T1DM. Additionally, the study will also compare vit $\mathrm{D}$ deficiency with the glycemic control in patients with diabetes.

\section{Materials and Methods}

\section{Study design and participants}

The authors have selected retrospective research design with randomized selection of the participants. The study selected 226 participants from the territories of Jeddah, Saudi Arabia. All of the selected participants were the patients of T1DM. The participants were selected from the outpatient departments of "King Abdul Aziz University Hospital." This study was conducted between January 2013 and December 2013. 61.1\% of the participants were girls and $38.9 \%$ of the participants were boys. The minimum age of the participants was one year and the maximum year of the participants was 18 years. $10.5 \pm 3.8$ years were the calculated mean age of the participants. Comprehensive history and physical examination were done for the assessment of participants. Height, weight, and BMI of the patients were also assessed. Serum 25-hydroxyvitamin D [25(OH) D] and Hemoglobin Alc (HbAlc) levels were analyzed through laboratory investigations. Glycosylated hemoglobin was assessed through highperformance liquid chromatography.

Advanced laboratory approaches were used for assessing phosphate, calcium, and alkaline phosphate levels in the blood. For the assessment of HAlc for glycemic control, the participants were divided into three categories that include good glycemic control (HA1c $\leq 7 \%$ ), moderate glycemic control (HA1c $7.1-9 \%$ ), poor glycemic control (HA1c $>9$ $\%)$. The study divided the participants into three groups on the basis vit D levels within the human body. Participants, having the level of vit $\mathrm{D}$ $<30 \mathrm{nmol} / \mathrm{L}$, were included in group 1. Participants, having the level of vit $\mathrm{D}$ between the ranges of 30-49 $\mathrm{nmol} / \mathrm{L}$, were included in group 2 . Group 2 was named as the insufficient amount.

Patients, who had the level of vitamin $\mathrm{D} \geq 50 \mathrm{nmol} / \mathrm{L}$, were included in group 3. Group 3 was named as sufficient amount group. All of the participants were receiving intensive insulin therapy during the investigation. Patients $<1$ year of age were excluded from this research project. The patients, having malnutrition, liver disease, and end stage renal disease were also excluded from the study. Demographic information was obtained along with the information regarding physical activity, occupation, place of residence, education level, family income, and type of house. Ethical committee of King Abdul Aziz University Hospital approved this research project before the data collection. This evidence based study was completely based upon Helsinki Declaration. Informed consent was signed from each participant of the study.

SPPS version 13 was used for performing statistical analysis of the gathered data (SPSS Inc., Chicago, IL, USA). ANOVA and t-test were used for contrasting average values with each other. ANOVA is considered as an extremely common testing method, which refers to the analysis of variance. Furthermore, correlation analysis was also done during the analysis of data. Correlation analysis was helpful to evaluate the relationship between daily insulin requirement and 25 OHD levels. Mean \pm SD was used for expressing the results. The $p$ value of $<0.05$ was considered significant from the aspect of statistics.

\section{Results}

The study selected 226 diabetic children as the participants. $63.8 \%$ of the female participants were pubertal; however, $36.2 \%$ of the female participants were pre-pubertal. Table 1 is presenting complete information about the distribution of selected participants on the basis of age groups at the time of diagnosis and evaluation. The findings of this study have also shown that $48.2 \%$ of the diabetic patients were suffering from the condition of vitamin D deficiency.

It was also evaluated that $28.8 \%$ of the diabetic participants had insufficient amount of vit D in their human body. However, $23 \%$ of the diabetic participants had normal levels of vit $\mathrm{D}$. Therefore, it can be said that $77 \%$ of the diabetic patients had reduced levels of vit $\mathrm{D}$. An appropriate relationship was also identified between $\mathrm{HbAlc}$ and the status of vitamin D among the selected diabetic patients (Table 2).

\begin{tabular}{|c|c|c|c|c|c|c|c|c|c|}
\hline & \multicolumn{2}{|c|}{ Vitamin D deficiency } & \multicolumn{2}{|c|}{ Vitamin D insufficiency } & \multicolumn{2}{|c|}{ Vitamin D sufficiency } & \multicolumn{2}{|c|}{ Total } & \multirow[t]{2}{*}{$P$ value } \\
\hline & $\mathrm{N}$ & $\%$ & $\mathrm{~N}$ & $\%$ & $N$ & $\%$ & $\mathrm{~N}$ & $\%$ & \\
\hline \multicolumn{10}{|l|}{ Age in years } \\
\hline$<5$ & 11 & 52.4 & 2 & 9.5 & 8 & 38.1 & 21 & 9.3 & $<0.05$ \\
\hline $5-10$ & 15 & 24.6 & 23 & 37.7 & 23 & 44.7 & 61 & 26.9 & \\
\hline $10-15$ & 64 & 57.1 & 33 & 29.5 & 15 & 15.4 & 112 & 49.5 & \\
\hline$>15$ & 19 & 59.4 & 7 & 21.9 & 6 & 18.8 & 37 & 16.3 & \\
\hline \multicolumn{10}{|l|}{ Gender } \\
\hline Male & 45 & 51.1 & 22 & 25 & 21 & 23.9 & 88 & c & $>0.05$ \\
\hline Female & 64 & 46.4 & 43 & 31.2 & 31 & 22.5 & 138 & 61.1 & \\
\hline \multicolumn{10}{|c|}{ Duration of diabetes } \\
\hline$<5$ years & 71 & 47.9 & 40 & 27 & 37 & 25 & 148 & 65.4 & $>0.05$ \\
\hline$>5$ years & 38 & 48.7 & 25 & 32 & 15 & 19.2 & 78 & 34.6 & \\
\hline \multicolumn{10}{|l|}{ HA1c } \\
\hline Good control & 15 & 51.7 & 5 & 17.2 & 9 & 31 & 29 & 12.8 & $<0.05$ \\
\hline $\begin{array}{c}\text { Moderate } \\
\text { control }\end{array}$ & 22 & 36.6 & 18 & 30 & 20 & 33.3 & 60 & 26.5 & \\
\hline Poor control & 72 & 52.5 & 42 & 30.6 & 23 & 16.7 & 137 & 60.7 & \\
\hline
\end{tabular}

Table 1: Characteristics of the studied groups. 


\begin{tabular}{|c|c|c|c|c|c|}
\hline \multirow[b]{2}{*}{ HA1c } & \multirow[b]{2}{*}{ Mean } & \multirow{2}{*}{$\begin{array}{l}\text { Standard } \\
\text { deviation }\end{array}$} & \multicolumn{2}{|c|}{$95 \%$ confidence interval } & \multirow[b]{2}{*}{$P$ value } \\
\hline & & & Lower bound & $\begin{array}{l}\text { Upper } \\
\text { bound }\end{array}$ & \\
\hline Vitamin D deficiency & 10.4 & 2.3 & 9.9 & 10.8 & \multirow{3}{*}{$<0.05$} \\
\hline Vitamin D insufficiency & 9.5 & 1.9 & 9.1 & 10 & \\
\hline Vitamin D sufficiency & 8.8 & 1.7 & 8.3 & 9.2 & \\
\hline
\end{tabular}

Table 2: Mean and standard deviation of HA1c in the studied groups.

\begin{tabular}{|c|c|c|c|c|}
\hline & $\begin{array}{c}\text { Vitamin D } \\
\text { deficiency }\end{array}$ & $\begin{array}{c}\text { Vitamin D } \\
\text { insufficiency }\end{array}$ & $\begin{array}{c}\text { Vitamin D } \\
\text { sufficiency }\end{array}$ & P value \\
\hline Serum calcium( Mmol/L) & $2.2 \pm 0.03$ & $2.3 \pm 0.02$ & $2.3 \pm 0.04$ & $>0.05$ \\
\hline Serum phosphate(Mmol/L) & $1.4 \pm 0.02$ & $1.5 \pm 0.03$ & $1.4 \pm 0.05$ & $>0.05$ \\
\hline Alkaline phosphatase(Units/L) & $202 \pm 127$ & $230 \pm 92$ & $218 \pm 100$ & $>0.05$ \\
\hline Parathormone (Pg/ml) & $8.1 \pm 5.5$ & $7.1 \pm 4.3$ & $3.1 \pm 2.5$ & $<0.05$ \\
\hline
\end{tabular}

Table 3: Bone function profile and parathormone hormone in studied groups.

The $\mathrm{p}$ value was set at 0.05 . The findings have also described that $66 \%$ of the deficiency cases had extremely poor glycemic control and $57.1 \%$ of the patients had the deficiency of vitamin $\mathrm{D}$ between the age of 10 years and 15 years. However, $29.5 \%$ participants had inadequate amount of vitamin D deficiency among the similar age group. Differences were not identified among the three groups of diabetic patients in relation with serum phosphorus, serum calcium, and alkaline phosphate. On the contrary, a proper relationship was identified by this study between the developed groups in relation with parathormone hormone. Table 3 is showing complete details about this relationship.

For the purpose of evaluating the role of confounding factors on the results acquired, multivariate regression model is useful. The model assists to predict various outcomes on the set of values and variables. Such techniques examine the multiple variables impact (factors and covariates) in a similar model. One shall probably possess limited subject numbers in substrata, due to which the size of sample is often a big issue and analysis becomes impossible. When multiple confounding factors are concerned, then multiple variable regression investigation can be exceptionally valuable. It is considered to be efficient and it offers control of confounding when stratification fails due to small sample size.

\section{Discussion}

There are several studies which have assessed and discussed the rate of incidence of vit $\mathrm{D}$ deficiency among the masses. The reports reveled by various studies showed that the highest rate of deficiency of vitamin $\mathrm{D}$ is $90.6 \%$. On the other hand the lowest rates of deficiency of vit $\mathrm{D}$ are $15 \%$ [3-7]. A comprehensive study was conducted by some investigators of Saudi Arab, who explored the relationship between deficiency of vitamin $\mathrm{D}$ and diabetes mellitus. The results of this study yielded the same results as this current study estimated. It has been evaluated that $84 \%$ of diabetic participants were also coping with the state of vit D deficiency [13]. This study has mentioned that $77 \%$ of the diabetic patients had impaired levels of vit D. The study further described that $28.8 \%$ of the patients had insufficient levels; however, $48.2 \%$ of the patients were deficient of vit D. Another past study has also supported the findings of this study, which was conducted among the population of USA. The past study claimed that $76 \%$ of the participants had $25 \mathrm{OHD}$ levels $<30 \mathrm{ng} / \mathrm{ml}$. The past study further stated that the concentration of $25 \mathrm{OHD}$ was negatively connected with the factor of age [4].

A study was conducted in the healthcare institutes of Qatar where the diabetic patients were selected for the study. This study also focused on the increase in the incidence rate of the vit D deficiency in the selected participants. The results revealed that the deficiency rate of vit D was found to be $90.6 \%$. A Swiss study was conducted, which have shown the incidence rate of vit $\mathrm{D}$ deficiency equal to $60.5 \%{ }^{6}$. The incidence rate of vit $\mathrm{D}$ deficiency is Australia, Italy, and North America $43 \%, 25 \%$ and, $15 \%$ correspondingly [3,4,12]. Likewise, geographic and latitude environment have the capability to make a direct impact on variant incidence rate. The lower level of vit $\mathrm{D}$ can occur among diabetic patients due to the presence of a pre-existing vit $\mathrm{D}$ insufficiency status, which played a role of contributing factor in the development of T1DM.

The different incidence rates of vitamin D deficiency in TIDM patients can be caused due to various reasons. The reasons can be altered dietary habits or lack of exposure to sunlight. This can also be explained by the fact that variance in levels of vit $D$ is related to the occurrence of malabsorptive state among the patients with Type 1 Diabetes. This in turn will lead the patients towards the decreased levels of vitamin D. It is evidently described that vit $\mathrm{D}$ can prevent the death of islet cells [14]. Thus, there is a direct association among dysfunctioning of beta cells, hypovitaminosis $\mathrm{D}$, and resistance towards insulin $[15,16]$. It has been mentioned that vitamin $\mathrm{D}$ is effective for making positive improvements in the production of insulin [1]. Furthermore, the connection between $\mathrm{HbA1c}$ and vitamin $\mathrm{D}$ can also occur because of influencing vit $\mathrm{D}$ outcomes on insulin from beta cells, systemic inflammation, and actions of insulin [15].

It has been further described by the research studies that the poor nutritional and ineffective status of the patients will directly affect the glucose level of the blood. Thus, it is said that the diabetes mellitus and vit $\mathrm{D}$ are connected with each other. Current study has identified a major connection between vitamin $\mathrm{D}$ and $\mathrm{HbA1c}$ among the participants. $66 \%$ participants of this study had poor control (HbAlc $>9 \%$ ). Two investigational projects have exposed that reduced serum $25(\mathrm{OH}) \mathrm{D}$ levels had a close relationship with improper metabolic control among diabetic patients $[4,5]$. A past study has not described any difference between vitamin $\mathrm{D}$ and $\mathrm{HbA1c}$ levels among diabetic children [6].

This project disclosed that $57.1 \%$ of the participants were between the ages of 10-15 and were having decreased levels of vitamin D. On the other hand, $29.5 \%$ of the participants had insufficient levels of vit $\mathrm{D}$ and their ages were also between 10-15 years of age. A past research study has analyzed altered processes of vit $\mathrm{D}$ in 1,25(OH) $2 \mathrm{D} 3$ plasma. The study also highlighted increased 24, 25-dihydroxyvitamin D levels in the diabetic patients as compared to other participants [17]. Another past study has mentioned that early puberty is directly associated with the reduced levels of vit D. Sugar free colas have been identified as the major causative factor for vit D deficiency [18]. This research study discovered that the boys have high levels of vitamin $\mathrm{D}$ as compared to the girls. Only $38.5 \%$ of the boys were vit $\mathrm{D}$ deficient, whereas $61.5 \%$ of the girls had inadequate amounts of vit D. While, results of a similar past study affirmed that the girls have more tendency of coping up with the deficiency of vit $\mathrm{D}$ in comparison to the boys [19].

Similarly, the difference in ALP, phosphorus, and calcium were not identified in the groups. Therefore, it can be said that the increased levels of PTH is associated with the secondary response of decreased amount of vitamin $\mathrm{D}$, which will lead to reduced levels of calcium. A study was conducted in Egypt, which evaluated similar findings. The precedent study has described that diabetic patients had increased PTH levels along with the reduced amount of calcium and $25(\mathrm{OH})$ vitamin D levels. Results of the past study have shown that $52.85 \%$ of the participants had reduced vitamin levels; however, 
$30.65 \%$ of the participants had increased levels of PTH [20]. Another past study has mentioned the relationship among BMD, metabolic control, turnover markers, and bone anabolic. The study mentioned no difference between BMD and vitamin D levels [21]. With regards to the association between vitamin D deficiency, and glycemic control, limited studies are available indicating the role of pre-diabetes and family history. According to Ciccone, general perspective can be gained on complicated relationship between pre-diabetes and family history of diabetes along with onset of cardiovascular diseases [22]. People having high risk of suffering from diabetes (i.e. having a family history) should be appropriately tested. People with impaired glucose tolerance and impaired fasting glucose are thought to have pre-diabetic condition. The condition of pre-diabetes is also linked with other metabolic syndrome and obesity. In diabetic patients, vitamin D administration has been demonstrated to diminish the resistance of insulin.

Dutta et al., documented similar observation among pre-diabetic individuals. The OVERT diabetes enhances the rates of mortality among individuals due to its pathogenesis. Within the literature, limited information exists about the pre-diabetes role and family diabetes history in determining the general population outcomes [23]. Conversely, family history of this condition is not relevant to boost in the alteration of metabolites predisposing the overt diabetes onset, however it is considered to overcome changes caused endocrinologically along with provoking untimely lesions within vascular walls. Hence, an individual's cardiovascular risk profile is enhanced due to family history of diabetic condition. DAISY study (Diabetes Autoimmunity Study in the Young) recruited children with increased type 1 diabetes risk, as examined by family history of T1DM and HLA-DR genotype. Hence, a protective impact of vitamin D was observed when it was taken as food and not as a supplement.

Various other pharmacological interventions and insulin is capable of controlling other aspects of diabetes. They tend to insufficiently prevent microvascular complications and atherothrombosis affecting the lens, retina, and kidney. Conversely, a range of other nutraceutical compounds may possess potential efficiency. Numerous concern areas exists with dietary supplements usage and nutraceuticals in patients with metabolic syndrome and diabetes comprising of finest dosing regimen, product standardization, drug interactions, potential side effects, and requirements for indications that are evidence based [24].

Augmented intake of Vitamin D by infants diminished the threat of developing the condition of type 1 diabetes. Around 33 percent reduction was observed in childhood-onset T1DM was observed in children receiving the vitamin $\mathrm{D}$ supplementation in comparison to children who did not receive supplementation [25]. On the other hand, Danescu et al. conducted an open label randomized control trial in which adults with the current type 1 diabetes onset were recruited. A supplementation benefit with calcitriol was examined which tend to reduce required dose of insulin temporarily [26]. The sufficiency of Vitamin D can be offered to the diabetic individuals demonstrating a positive impact on various physiological methods all through the body. Two servings a fiber a day in the form of supplements, cereals, and whole foods have been demonstrated to diminish the diabetes risk. When it comes to the supplements of nutraceutical, it is important to beware [27].

Another nutraceutical "Acarbose" can also be taken under consideration. It is $\alpha$-glucosidase inhibitor which is well known to diminish consequent diabetes incidences over a follow up period of 4 years i.e. about twenty five percent. The usual agent that slows down the absorption of carbohydrate may mimic the defensive Acarbose effect.
It comprises of chlorogenic acid, soluble fiber (glucomannan), legumederived $\alpha$-amylase inhibitors, and chlorogenic acid [28].

\section{Conclusion}

Vitamin D plays a significant role in regulating various processes of a human body. Deficiency of vitamin D can lead to serious complication in a human body, both in adults and children. It has been deduced by the study that people suffering from diabetes have high occurrence rate of vitamin $\mathrm{D}$, as the occurrence of vitamin $\mathrm{D}$ is directly related to glycemic control. Increased level of glucose in blood can be controlled by taking various supplement of vitamin $\mathrm{D}$. Therefore, it can be concluded that gauging the level of vitamin $\mathrm{D}$ deficiency in diabetic patients is very critical. Some limitations of the study are impaired frequencies of calcium rich diet, and exposure to sunlight (duration). The main limitation of the study consists of its retrospective design. It was difficult to compute population based rates and the number of selected Type 1 diabetes participants was small. Lastly, variations in intake of vitamin $\mathrm{D}$ due to different seasons can also be regarded as a limitation to this study.

\section{References}

1. Chiu KC, Chu A, Go VL, Saad MF (2004) Hypovitaminosis D is associated with insulin resistance and beta cell dysfunction. Am J Clin Nutr 79: 820-825.

2. Norman AW, Frankel JB, Heldt AM, Grodsky GM (1980) Vitamin D deficiency inhibits pancreatic secretion of insulin. Science 209: 823-825.

3. Greer RM, Rogers MA, Bowling FG, Buntain HM, Harris M, et al. (2007) Australian children and adolescents with type 1 diabetes have low vitamin $D$ levels. Med J Aust 187: 59-60.

4. Svoren BM, Volkening LK, Wood JR, Laffel LM (2009) Significant vitamin D deficiency in youth with T1D mellitus. J Pediatr 154: 132-134.

5. Tunc O, Cetinkaya S, Kizilgun M (2010) Evaluation of the relation between vitamin $\mathrm{D}$ and insulin requirements and frequency of osteopenia/osteoporosis in childhood with type 1 diabetes. $49^{\text {th }}$ Annual Meeting of the ESPE. 22-25.

6. Janner M, Ballinari P, Mullis PE, Flück CE (2010) High prevalence of vitamin D deficiency in children and adolescents with type 1 diabetes. Swiss Med Wkly 140: w13091.

7. Bener A, Alsaied A, Al-Ali M, Al-Kubaisi A, Basha B, et al. (2009) High prevalence of vitamin $D$ deficiency in type 1 diabetes mellitus and healthy children. Acta Diabetol 46: 183-189.

8. Hewison $M(2010)$ Vitamin $D$ and the immune system: new perspectives on an old theme. Endocrinol Metab Clin North Am 39: 365-379.

9. Mohr SB, Garland CF, Gorham ED, Garland FC (2008) The association between ultraviolet $B$ irradiance, vitamin $D$ status and incidence rates of type 1 diabetes in 51 regions worldwide. Diabetologia 51: 1391-1398.

10. Kositsawat J, Freeman VL, Gerber BS, Geraci S (2010) Association of A1C levels with vitamin D status in U.S. adults: data from the National Health and Nutrition Examination Survey. Diabetes Care 33: 1236-1238.

11. Holick MF, Binkley NC, Bischoff-Ferrari HA, Gordon CM, Hanley DA, et al. (2011) Evaluation, treatment, and prevention of vitamin D deficiency: an Endocrine Society clinical practice guideline. The Journal of Clinical Endocrinology \& Metabolism 96: 1911-1930.

12. Pozzilli $P$, Manfrini S, Crinò A, Picardi A, Leomanni C, et al. (2005) Low levels of 25-hydroxyvitamin D3 and 1,25-dihydroxyvitamin D3 in patients with newly diagnosed type 1 diabetes. Horm Metab Res 37: 680-683.

13. Bin-Abbas BS, Jabari MA, Issa SD, Al-Fares AH, Al-Muhsen S (2011) Vitamin $D$ levels in Saudi children with type 1 diabetes. Saudi Med J 32: 589-592.

14. Riachy R, Vandewalle B, Moerman E, Belaich S, Lukowiak B, et al. (2006) 1,25-Dihydroxyvitamin D3 protects human pancreatic islets against cytokineinduced apoptosis via down-regulation of the Fas receptor. Apoptosis 11: 151 159

15. Lind L, Hänni A, Lithell H, Hvarfner A, Sörensen $\mathrm{OH}$, et al. (1995) Vitamin D is related to blood pressure and other cardiovascular risk factors in middle-aged men. Am J Hypertens 8: 894-901. 
Citation: Al-Agha AE, Ahmad IA (2015) Association among Vitamin D Deficiency, Type 1 Diabetes Mellitus and Glycemic Control. J Diabetes Metab 6: 594. doi:10.4172/2155-6156.1000594

Page 5 of 5

16. Boucher BJ, Mannan N, Noonan K, Hales CN, Evans SJ (1995) Glucose intolerance and impairment of insulin secretion in relation to vitamin $D$ deficiency in east London Asians. Diabetologia 38: 1239-1245.

17. Rødland O, Markestad T, Aksnes L, Aarskog D (1985) Plasma concentrations of vitamin D metabolites during puberty of diabetic children. Diabetologia 28: 663-666.

18. Bowman SA (2002) Beverage choices of young females: changes and impact on nutrient intakes. J Am Diet Assoc 102: 1234-1239.

19. Alshamsan F, Elgabry E, Bin- Abbas B (2014) Vitamin D Deficiency is Comparatively More Prevalent in Female Children with Type 1 Diabetes in a High Vitamin D Deficiency Risk Country Middle East Journal Of Family Medicine 12: 30-37.

20. Hamed EA, Faddan NH, Elhafeez HA, Sayed D (2011) Parathormone--25(OH)vitamin $D$ axis and bone status in children and adolescents with type 1 diabetes mellitus. Pediatr Diabetes 12: 536-546.

21. Simmons JH, Raines M, Ness KD, Hall R, Gebretsadik T, et al. (2011) Metabolic control and bone health in adolescents with type 1 diabetes. Int J Pediatr Endocrinol 2011: 13.
22. Ciccone MM, Scicchitano P, Cameli M, Cecere A, Cortese F, et al. (2014) Endothelial function in pre-diabetes, diabetes and diabetic cardiomyopathy: a review. J Diabetes Metab 5: 2.

23. Dutta D, Maisnam I, Shrivastava A, Sinha A, Ghosh S, et al. (2013) Serum vitamin-D predicts insulin resistance in individuals with prediabetes. Indian $\mathrm{J}$ Med Res 138: 853-860

24. Marra MV, Boyar AP (2009) Position of the American Dietetic Association: nutrient supplementation. J Am Diet Assoc 109: 2073-2085.

25. (1999) Vitamin D supplement in early childhood and risk for Type I (insulindependent) diabetes mellitus. The EURODIAB Substudy 2 Study Group. Diabetologia 42: 51-54

26. Danescu LG, Levy S, Levy J (2009) Vitamin D and diabetes mellitus. Endocrine 35: 11-17.

27. Scicchitano P, Cameli M, Maiello M, Modesti PA, Muiesan ML, et al. (2014). Nutraceuticals and dyslipidaemia: Beyond the common therapeutics. Journal of Functional Foods 6: 11-32.

28. McCarty MF (2005) Nutraceutical resources for diabetes prevention--an update. Med Hypotheses 64: 151-158. 